\section{Fatal Brazilian Spotted Fever Associated with Dogs and Amblyomma aureolatum Ticks, Brazil, 2013}

\author{
Elisa S.M.M. Savani, Francisco B. Costa, \\ Elisabete A. Silva, Ana C.F. Couto, \\ Melanie Gutjahr, Juliana N.M.O. Alves, \\ Fabiana C.P. Santos, Marcelo B. Labruna
}

Author affiliations: Prefeitura de São Paulo, São Paulo, Brazil

(E.S.M.M. Savani, E.A. Silva, A.C.F. Couto, M. Gutjahr, J.N.M.O. Alves); Universidade de São Paulo, São Paulo (F.B. Costa, M.B. Labruna); Instituto Adolfo Lutz, São Paulo (F.C.P. Santos)

DOI: https://doi.org/10.3201/eid2512.191146

In São Paulo metropolitan area, Brazil, Amblyomma aureolatum ticks are the main vector of Rickettsia rickettsii, which causes Brazilian spotted fever. In 2013, a boy in São Paulo died of Brazilian spotted fever associated with household $\operatorname{dogs}$ and $A$. aureolatum ticks. Prompt recognition and treatment of this illness might prevent deaths.

$\mathrm{T}$ he bacterium Rickettsia rickettsii is the etiologic agent of Rocky Mountain spotted fever; in Brazil, this illness is called Brazilian spotted fever and is a national notifiable tickborne disease with fatality rates $\approx 50 \%(1,2)$. Since the 1920 s, the vector of $R$. rickettsii in the southern São Paulo metropolitan area has been the Amblyomma aureolatum tick $(3,4)$. In this area, free-roaming domestic dogs (major hosts of A. aureolatum ticks) are presumed to play a role in carrying $R$. rickettsii-infected ticks from forest fragments (A. aureolatum tick habitat) to household interiors $(4,5)$. Dogs could thus be associated with the higher incidence of Brazilian spotted fever in women and children, who usually spend more time indoors, in close contact with dogs (5).

In November 2013, a 12-year-old boy died after 8 days of an acute febrile illness. He lived in the neighborhood of Sete Praias, near Atlantic forest remnants in the southern São Paulo metropolitan area. On day 3 of illness, he was admitted to the Nasf-Unifesp Hospital in the city of São Paulo with fever (temperature $39.5^{\circ} \mathrm{C}$ ), headache, nausea, asthenia, and abdominal rash. The patient's mother informed the physician that her son had been bitten by a tick on his nape $\approx 1$ week before disease onset; the tick was removed and discarded. The boy was medicated with dipyrone and sent home. On day 6 , the patient was returned to the hospital, unconscious, with jaundice and seizures. He was transferred to the intensive care unit; meningitis was suspected. The next day, his condition worsened, and when hematologic and biochemical examinations indicated thrombocytopenia and hepatic alterations, meningitis was ruled out. A blood serum sample was submitted for leptospirosis and spotted fever testing by serologic and molecular analysis, respectively. Results for leptospirosis were negative. The patient died on day 8 of illness. While the body was being prepared for the funeral, a tick was found attached behind the ear and was sent to the laboratory of the Prefeitura de São Paulo, where it was identified as an $A$. aureolatum unengorged female.

DNA extracted from the serum sample by use of PureLink Viral RNA/DNA Mini Kit (Invitrogen, https://www. thermofisher.com) was positive by Taqman real-time PCR for the genus Rickettsia (6). We therefore next performed 2 conventional PCRs, 1 targeting a 401-bp fragment of the rickettsial gltA gene (7) and the other targeting a 631-bp fragment of the rickettsial ompA gene (8). Both yielded amplicons that, after DNA sequencing, had sequences $100 \%$ identical to $R$. rickettsii (GenBank accession no. CP003305) by BLAST analyses (http://blast.ncbi.nlm.nih.gov/Blast.cgi).

Immediately after the patient's death, the hospital notified the São Paulo Board of Health of this case, and we performed an epidemiologic investigation. In the patient's household, we collected blood samples from 3 dogs and 11 cats, all adults, born and raised in the area, with free access to surrounding forests and the dwelling interior. Direct contact between the patient and his pets was reportedly common. Serum from the dogs and cats was tested for $R$. rickettsii $\operatorname{IgG}$ by immunofluorescence assay, as described (3). Seroreactivity was detected in the 3 dogs (endpoint titers 512, 2,048, and 4,096 ) and 3 of the cats (titers 64, 64, and 512).

During animal sampling, we collected 13 ticks from 1 dog and 1 tick from 1 cat; all ticks were $A$. aureolatum adults. These 14 ticks, plus the 1 from the patient's body, were submitted for DNA extraction (5) and tested by the same 2 conventional PCRs. Two ticks (1 from the dog and the 1 from the patient) yielded glt $A$ and $o m p A$ amplicons, which generated DNA sequences $100 \%$ identical to $R$. rickettsii (CP003305).

This fatal case of Brazilian spotted fever was epidemiologically associated with $A$. aureolatum ticks and domestic dogs. Because the patient had no recent history of traveling outside his neighborhood, we infer that he acquired the infection in his neighborhood, where $R$. rickettsii was circulating between ticks and his dogs. Although the A. aureolatum tick collected postmortem from the patient harbored $R$. rickettsii, we cannot be sure that this particular tick was the primary vector of the bacterium to the patient because the tick would certainly have been exposed to an infected blood meal during the last days of the patient's life. We can, however, confirm that the patient was exposed in his neighborhood to A. aureolatum ticks, competent vectors of $R$. rickettsii (5). Because fed adult $A$. aureolatum ticks need only 10 minutes of attachment to transmit $R$. rickettsii to hosts (5), the likelihood 
of such transmission for this patient was high, considering his close contact with his pets. Had the physicians suspected Brazilian spotted fever when the boy was first admitted to the hospital on day 3 of febrile illness, treatment with appropriate antimicrobial drugs might have prevented his death (9).

This work was performed at the University of São Paulo, Prefeitura de São Paulo, and Adolfo Lutz Institute, São Paulo, SP, Brazil.

\section{About the Author}

Dr. Savani is an epidemiologist at the São Paulo City Board of Health. Her research interests are epidemiology and control of urban zoonoses.

\section{References}

1. Parola P, Paddock CD, Socolovschi C, Labruna MB, Mediannikov O, Kernif T, et al. Update on tick-borne rickettsioses around the world: a geographic approach. Clin Microbiol Rev. 2013;26:657-702. https://doi.org/10.1128/CMR.00032-13

2. de Oliveira SV, Guimarães JN, Reckziegel GC, Neves BM, Araújo-Vilges KM, Fonseca LX, et al. An update on the epidemiological situation of spotted fever in Brazil. J Venom Anim Toxins Incl Trop Dis. 2016;22:22.4 https://doi.org/10.1186/ s40409-016-0077-4

3. Ogrzewalska M, Saraiva DG, Moraes-Filho J, Martins TF, Costa FB, Pinter A, et al. Epidemiology of Brazilian spotted fever in the Atlantic Forest, state of São Paulo, Brazil. Parasitology. 2012;139:1283-300. https://doi.org/10.1017/S0031182012000546

4. Scinachi CA, Takeda GACG, Mucci LF, Pinter A. Association of the occurrence of Brazilian spotted fever and Atlantic rain forest fragmentation in the São Paulo metropolitan region, Brazil. Acta Trop. 2017;166:225-33. https://doi.org/10.1016/j.actatropica.2016.11.025

5. Saraiva DG, Soares HS, Soares JF, Labruna MB. Feeding period required by Amblyomma aureolatum ticks for transmission of Rickettsia rickettsii to vertebrate hosts. Emerg Infect Dis. 2014;20:1504-10. PubMed https://doi.org/10.3201/eid2009.140189

6. dos Santos FC, do Nascimento EM, Katz G, Angerami RN, Colombo S, de Souza ER, et al. Brazilian spotted fever: realtime PCR for diagnosis of fatal cases. Ticks Tick Borne Dis. 2012;3:312-4. https://doi.org/10.1016/j.ttbdis.2012.10.027

7. Labruna MB, Whitworth T, Horta MC, Bouyer DH, McBride JW, Pinter A, et al. Rickettsia species infecting Amblyomma cooperi ticks from an area in the state of São Paulo, Brazil, where Brazilian spotted fever is endemic. J Clin Microbiol. 2004;42:90-8. https://doi.org/10.1128/JCM.42.1.90-98.2004

8. Eremeeva ME, Bosserman EA, Demma LJ, Zambrano ML, Blau DM, Dasch GA. Isolation and identification of Rickettsia massiliae from Rhipicephalus sanguineus ticks collected in Arizona. Appl Environ Microbiol. 2006;72:5569-77. https://doi.org/10.1128/AEM.00122-06

9. Vilges de Oliveira S, Nogueira Angerami R. Timeliness in the notification of spotted fever in Brazil: evaluating compulsory reporting strategies and digital disease detection. Int J Infect Dis. 2018;72:16-8. https://doi.org/10.1016/j.ijid.2018.04.4317

Address for correspondence: Marcelo B. Labruna, Universidade de São Paulo, Departamento de Medicina Veterinária Preventiva e Saúde Animal, Faculdade de Medicina Veterinária e Zootecnia, Av. Prof. Orlando Marques de Paiva, 87 Cidade Universitaria, São Paulo, SP 05508-270, Brazil; email: labruna@usp.br

\section{Phylogenetic Analysis of Bird-Virulent West Nile Virus Strain, Greece}

\author{
George Valiakos, Konstantinos Plavos, \\ Alexandros Vontas, Marina Sofia, \\ Alexios Giannakopoulos, Themis Giannoulis, \\ Vassiliki Spyrou, Constantina N. Tsokana, \\ Dimitrios Chatzopoulos, Maria Kantere, \\ Vasilis Diamantopoulos, Angeliki Theodorou, \\ Spyridoula Mpellou, Athanasios Tsakris, \\ Zissis Mamuris, Charalambos Billinis
}

Author affiliations: University of Thessaly, Karditsa, Greece (G. Valiakos, K. Plavos, A. Vontas, M. Sofia, A. Giannakopoulos, T. Giannoulis, V. Spyrou, C.N. Tsokana, D. Chatzopoulos, M. Kantere, Z. Mamuris, C. Billinis); Public Health Director, Region of Peloponnese, Tripoli, Greece (V. Diamantopoulos); Directorate-General for Regional Agricultural Economics and Veterinary, Region of Peloponnese, Nafplio, Greece (A. Theodorou); Bioefarmoges Eleftheriou LP_Integrated Mosquito Control, Marathon, Greece (S. Mpellou); University of Athens, Athens, Greece (A. Tsakris)

DOI: https://doi.org/10.3201/eid2512.181225

We report the full polyprotein genomic sequence of a West Nile virus strain isolated from Eurasian magpies dying with neurologic signs in Greece. Our findings demonstrate the local genetic evolution of the West Nile virus strain responsible for a human disease outbreak in the country that began in 2010.

$\mathrm{W}$ est Nile virus (WNV) is the etiologic agent of an ongoing human disease outbreak in Greece since 2010. Until 2014, successive yearly outbreaks occurred mainly in central and northeastern Greece (1). After a 2-year hiatus, during July-October 2017, an outbreak of the disease occurred in the Peloponnese region in southern Greece that resulted in 48 laboratory-confirmed cases and 5 human deaths (2). In 2018, cases further expanded, with a total of 243 human cases and 50 deaths reported from various areas of Greece (3).

In June 2017, one month before human cases occurred, dead wild birds were reported in the Argolida regional unit in the Peloponnese region of Greece. Through mid-July, local residents noticed a reduction of the native wild bird population, especially Eurasian magpies (Pica pica), hooded crows (Corvus cornix), sparrows (Passer domesticus), and Eurasian collared doves (Streptopelia decaocto). Our team verified the presence of Eurasian magpies with neurologic signs in the area; affected birds were lethargic and 